\title{
Computational modelling to predict mechanosensing of fibroblast cells in response to different material properties
}

\author{
Wenjian Yang ${ }^{1}$, Ma Luo ${ }^{1}$, Yanfei $\mathrm{Gao}^{2}$, and Jinju Chen ${ }^{1}$ \\ ${ }^{1}$ Newcastle University \\ ${ }^{2}$ The University of Tennessee Knoxville
}

December 1, 2021

\begin{abstract}
We present a computational model of the mechanosensing of a fibroblast cell seeded on the materials with different stiffnesses and thicknesses. The model can predict the critical thickness of a given biomaterial that a cell can sense and the dynamic change of stress fibres and focal adhesions through its incorporation of the dynamic characteristics of stress fibre contraction and focal adhesion. We show that the cell-cell communication via elastic substrate induces the orientation of stress fibres. The cell-cell interaction through compliant substrate has a small but significant effect on enhancing the cell depth sensing capability in terms of interfacial displacement and stress fibre concentration. The framework developed here is important for a thorough understanding of processes where substrates are deformed such as in wound healing process and the design of bioactive coatings for tissue engineering.
\end{abstract}

\section{Hosted file}

manuscript.docx available at https ://authorea.com/users/448963/articles/547637-computationalmodelling-to-predict-mechanosensing-of-fibroblast-cells-in-response-to-differentmaterial-properties 
(a)

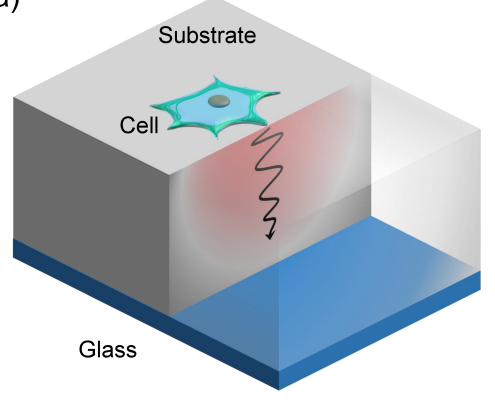

(c)

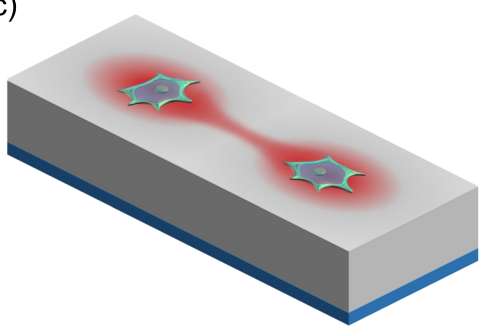

(a)

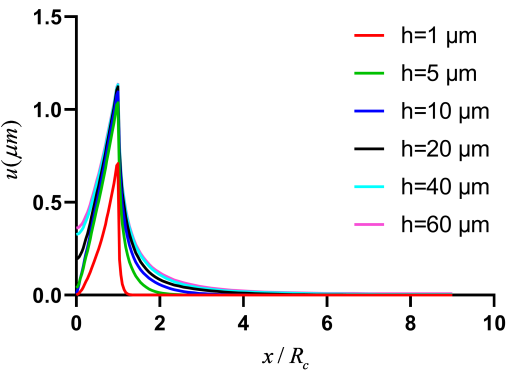

(c)

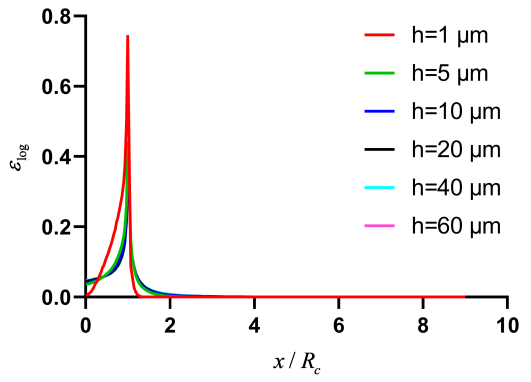

(b)

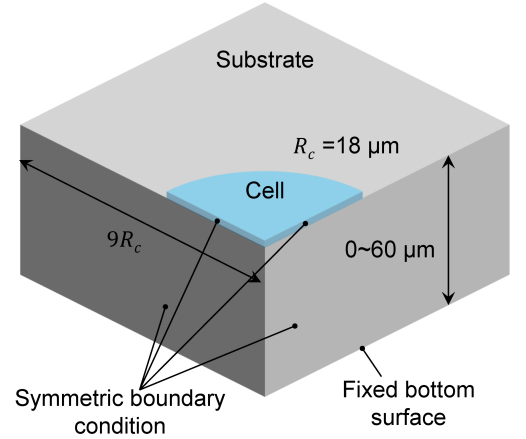

(d)

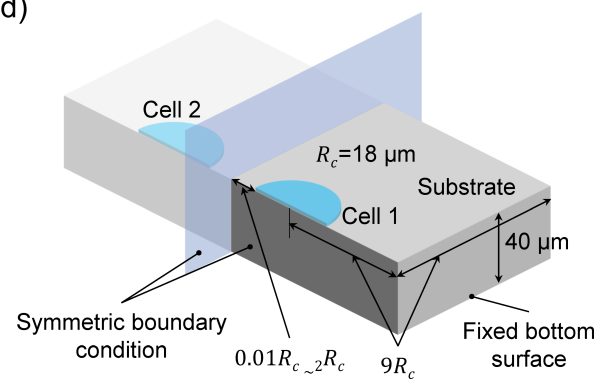

(b)

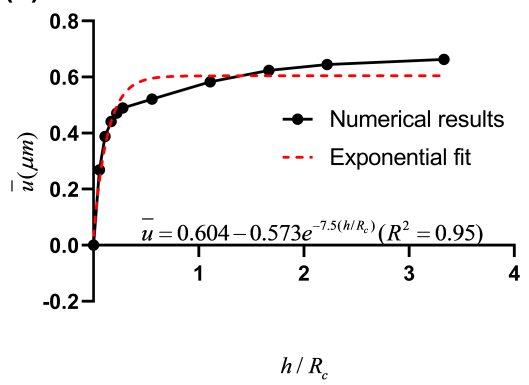

(d)

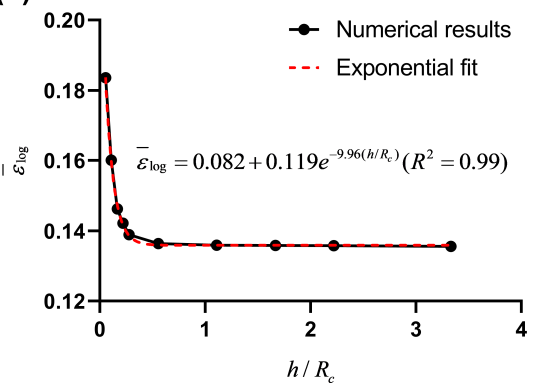


(a)

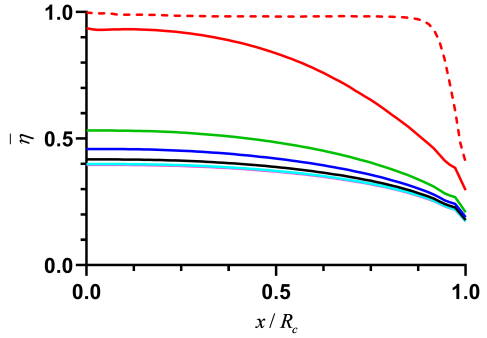

(a)

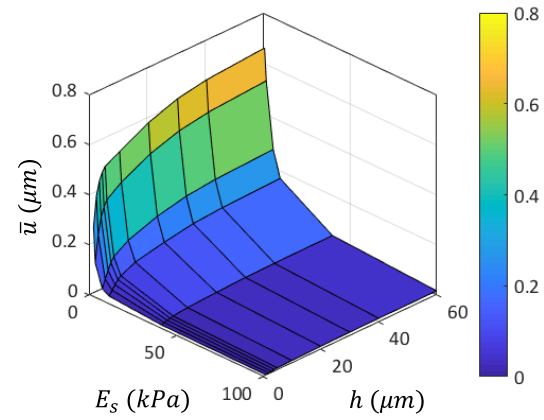

(c)

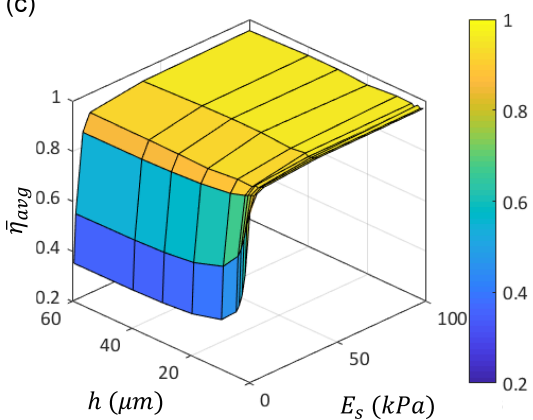

(b)
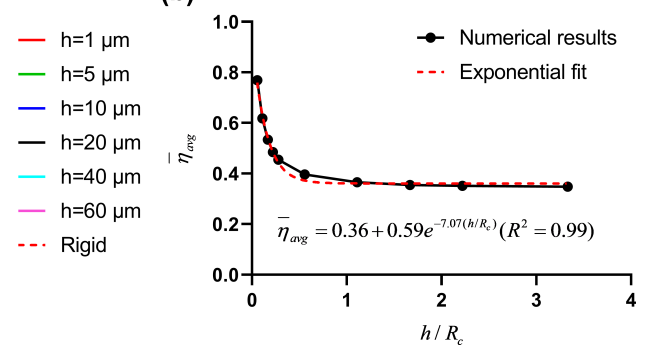

(b)

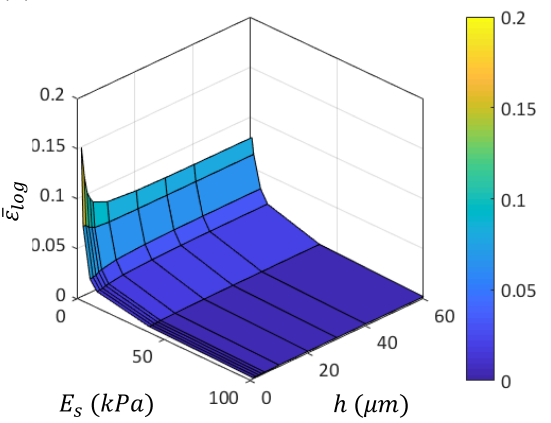

(d)

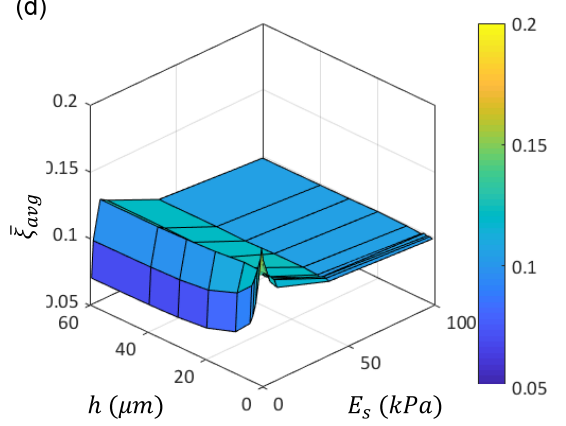


(a)

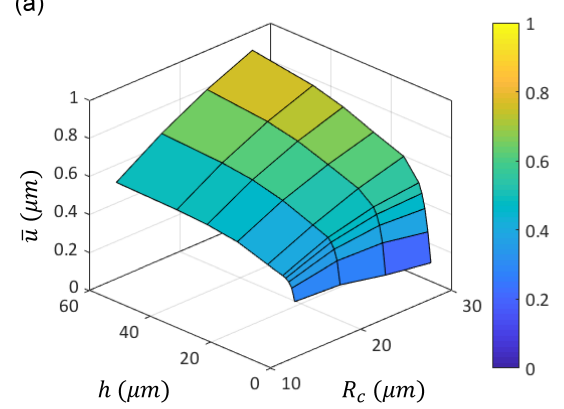

(c)

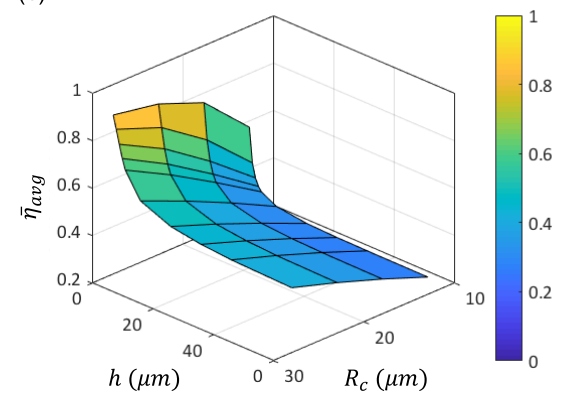

(a)

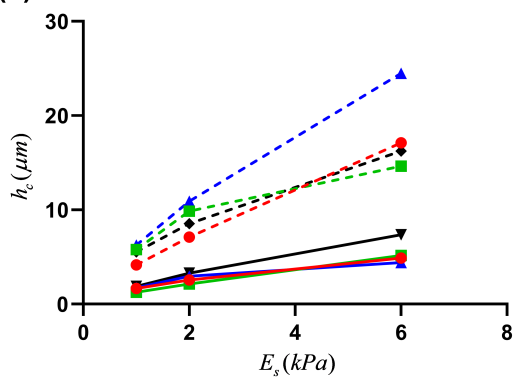

- Interfacial Displacement

-2- Interfacial Max. Principal Strain

$\mp$ SF Concentration

$\rightarrow$ SF Active Max. Principal Stress (b)

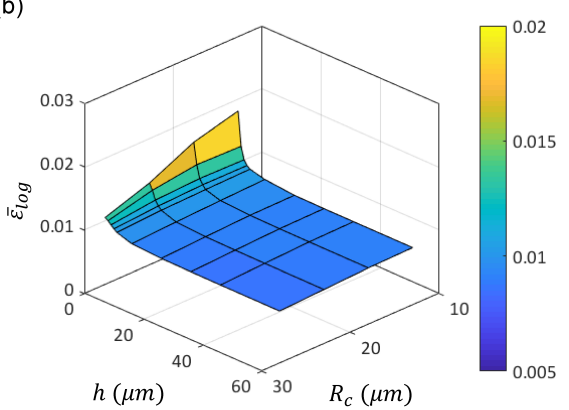

(d)

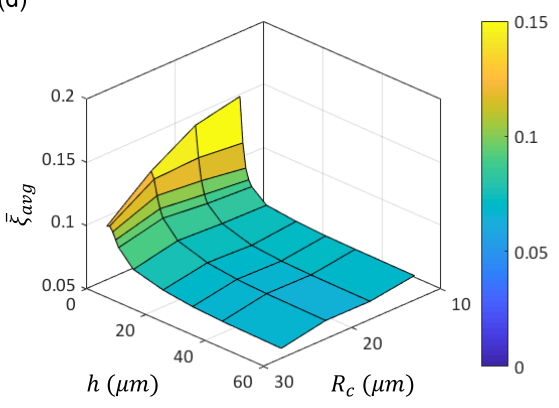

(b)

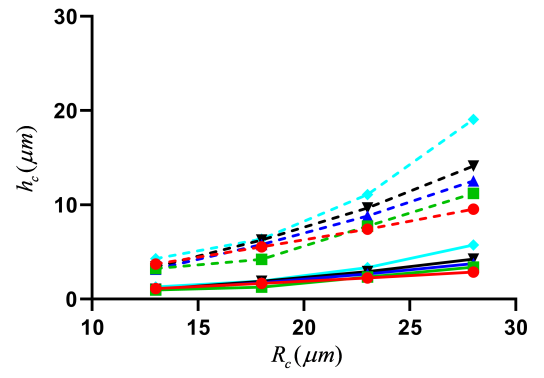

- Interfacial Displacement

-- Interfacial Max. Principal Strain

- SF Concentration

* SF Active Max. Principal Stress

$\rightarrow$ High Affinity Integrin Density 
(a)

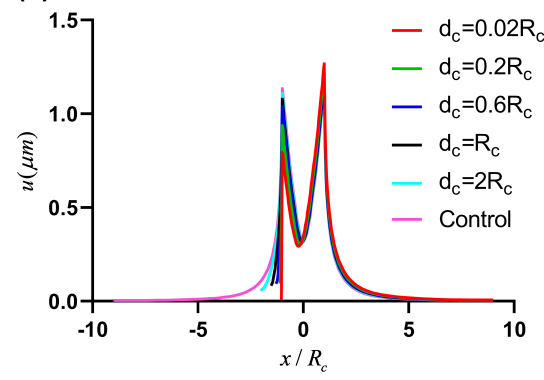

(c)

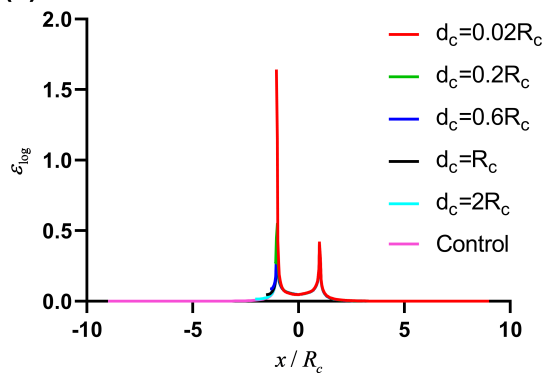

(a)

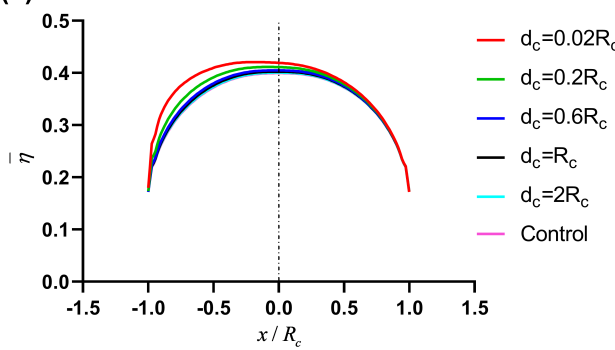

(c)

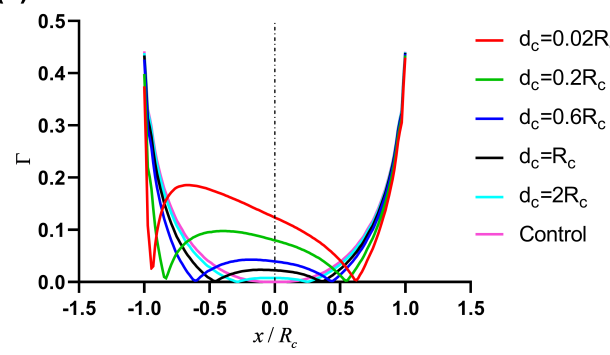

(b)

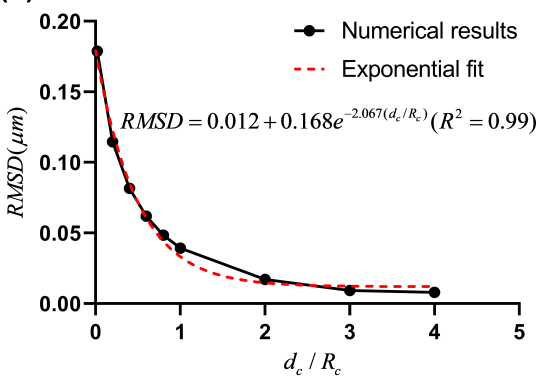

(d)

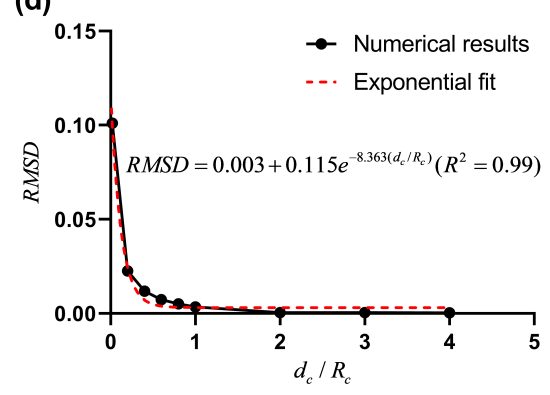

(b)

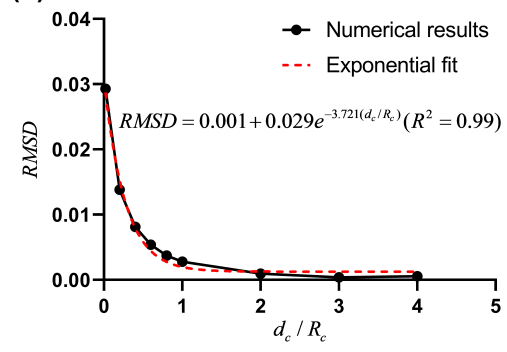

(d)

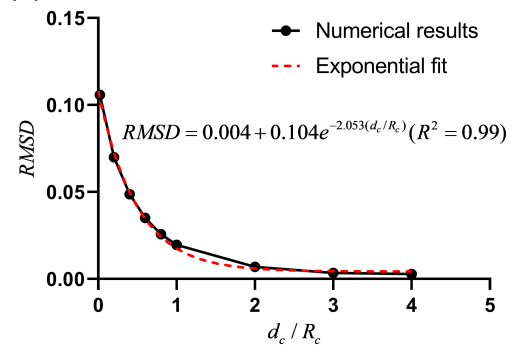



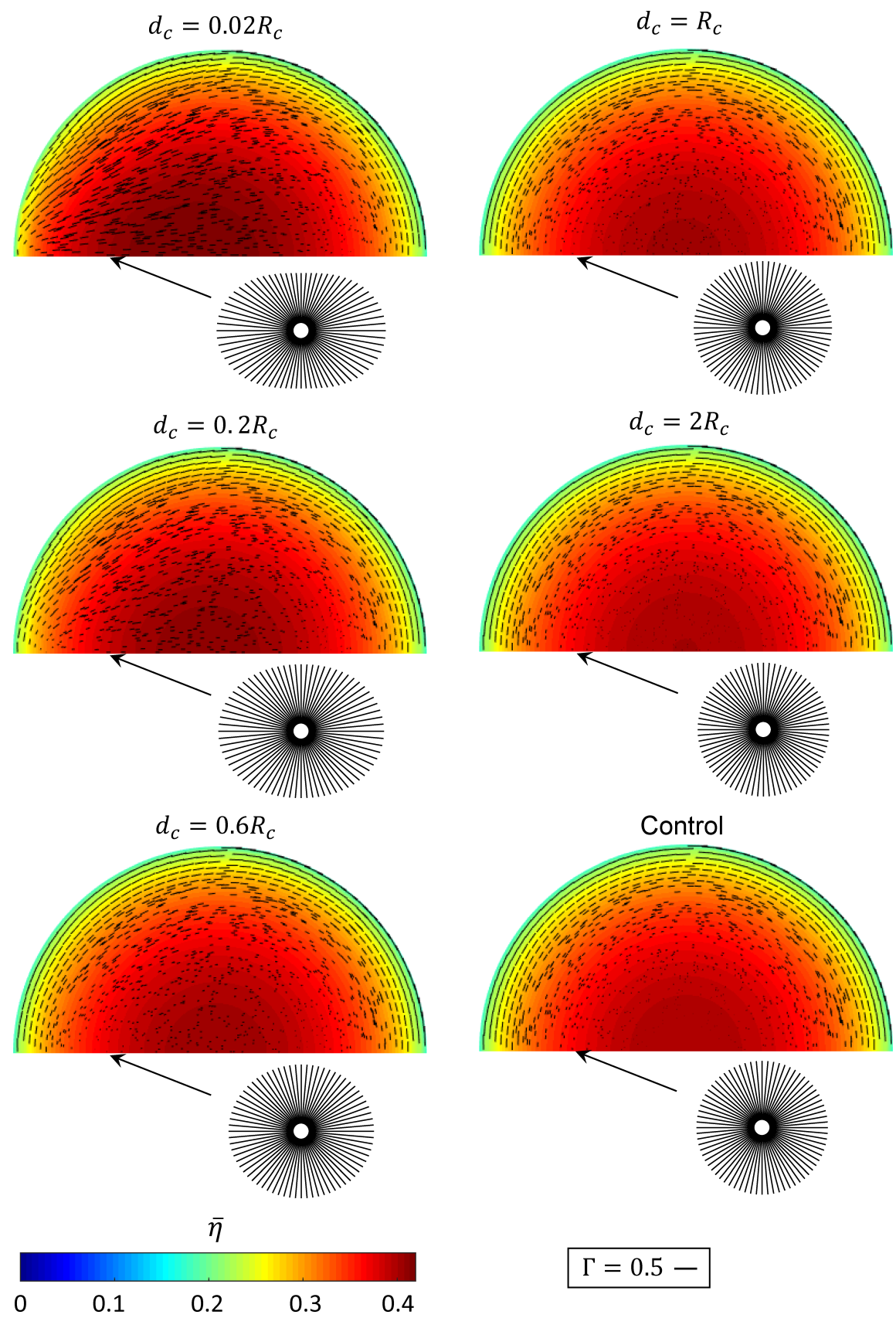

$\Gamma=0.5-$ 
(a)

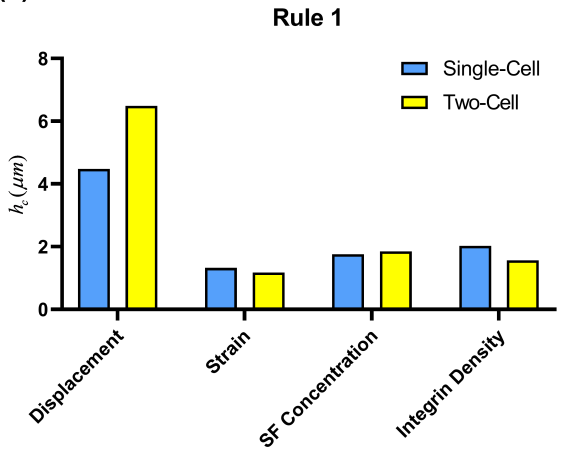

(b)

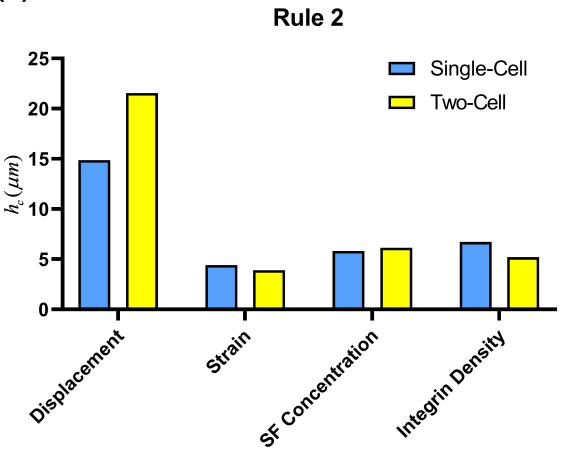

